Ensino

\title{
Promovendo a aprendizagem sobre infecções sexualmente transmissíveis por meio de uma sequência didática
}

\author{
Promoting learning about sexually transmitted infections through a \\ didactic sequence
}

\author{
Gemilton de Freitas Mesquita'(i), Aline Furtuozo de Souzal'(i), \\ Thais Soares da Silva"I(D, Isabella Macário Ferro Cavalcanti"li() \\ ' Universidade Federal de Pernambuco, Vitória de Santo Antão, PE, Brasil; \\ "Universidade Federal Rural de Pernambuco, Recife, PE, Brasil; \\ III Universidade Federal de Pernambuco, Recife, PE, Brasil; Universidade Federal de Pernambuco, Vitória \\ de Santo Antão, PE, Brasil.
}

\section{RESUMO}

Este artigo tem como objetivo contribuir com o processo de ensino-aprendizagem do tema Infecção Sexualmente Transmissível (IST) através da aplicação de sequência didática (SD) para alunos do ensino médio. O professor realizou uma SD composta por 10 aulas em 5 etapas. Iniciou-se com um jogo de tabuleiro, acompanhado por roda de conversa, leitura de textos e estudos de casos sobre ISTs com apresentação, em equipes, ao grande grupo. Seguida de aula expositiva e dialogada, além de aula interdisciplinar para o conhecimento e construção de livros paradidáticos. A avaliação do ensinoaprendizagem foi realizada através da análise de questionários prévio e pós SD, além da avaliação contínua apresentada pelo desenvolvimento do aluno ao longo da intervenção, sendo contemplados o processo investigativo e a autonomia do aluno. Observou-se grande aceitação e participação dos estudantes, além de uma média positiva do questionário avaliativo pós SD e a produção e desenvolvimento dos paradidáticos pelos quatro grupos formados, sendo concluído por duas das quatro equipes. Assim, a SD e a elaboração de um livro paradidático são ferramentas que podem auxiliar professores a formar alunos mais conscientes sobre questões relacionadas às ISTs e, consequentemente, terem uma postura mais crítica diante de questões cotidianas sobre as mesmas.

Palavras-chave: ISTs; Ensino; Sequência didática

\section{ABSTRACT}

This article aims to contribute to the teaching-learning process of the topic Sexually Transmitted Infection (STI) through the application of didactic sequence (SD) for high school students. The teacher performed a SD composed of 10 classes in 5 stages. It began with a board game, accompanied by talk wheel, reading texts and case studies on ISTs with presentation, in teams, to the large group. This is followed by an 
expository and dialogic class, as well as an interdisciplinary class for the knowledge and construction of books for children. The evaluation of teaching-learning was carried out through the analysis of previous questionnaires and SD post, besides the continuous evaluation presented by the development of the student throughout the intervention, being contemplated the investigative process and the autonomy of the student. There was a great acceptance and participation of the students, besides a positive average of the evaluation questionnaire post SD and the production and development of the paradidáticos by the four formed groups, being concluded by two of the four teams. Thus SD and the elaboration of a paradidático book are tools that can help teachers to train students more conscious about issues related to STIs and, consequently, to have a more critical posture when faced with daily questions about them.

Keywords: STI; Learning; Sequence didatic

\section{INTRODUÇÃO}

As Infecções Sexualmente Transmissíveis (ISTs) são infecções causadas por microrganismos como vírus, bactérias, fungos e protozoários, que podem ser transmitidas pelo contato íntimo (FARID et al., 2014). Essas infecções provocam danos a milhões de indivíduos, tais como infertilidade, câncer de colo de útero, disfunção sexual e doença inflamatória pélvica, contudo na maioria dos casos são infecções que não apresentam sintomas. As principais ISTs são AIDS, sífilis, gonorreia, hepatites B e C, herpes e o cancro mole. Todas essas doenças, exceto a AIDS, são curráveis e tem tratamento, porém se não tratadas podem levar o indivíduo a morte (AMORAS et al., 2015).

De acordo com a Organização Mundial de Saúde, estima-se que a nível mundial ocorram 340 milhões de novos casos de ISTs por ano. Dentre os países da América Latina, o Brasil apresenta quase metade de todos os novos casos de ISTs e é considerado um dos países com os mais elevados índices de casos de AIDS, atingindo quase 40 mil só em 2012 (SILVA et al., 2016). Entre os anos de 2006 e 2015, o Brasil quase que triplicou o quantitativo de indivíduos infectados pelo HIV (ARAGÃO, 2016), sendo o estado de Pernambuco o com maior número de ocorrências e com taxa acima da média nacional (MINISTÉRIO DA SAÚDE, 2016). Em torno de 10 a 12 milhões de novos casos de ISTs por ano são registrados no âmbito nacional, sendo assim considerado um grave problema de saúde pública, principalmente após a epidemia da AIDS na década de 1980. Ainda existem inúmeros casos de subnotificação tornando ainda deficitária os dados epidemiológicos sobre as ISTs. Essas infecções estão enquadradas em um dos cinco principais motivos de busca por serviços de 
saúde no Brasil e tem na sua população de adultos jovens uma maior vulnerabilidade ao HIV (SILVA et al., 2016).

Aproximadamente $17,5 \%$ da população mundial é formada por adolescente e correspondem a 23\% em países menos desenvolvidos (SENNA et al., 2015). No Brasil cerca de $30 \%$ da população se encontra na faixa dos 10 e 24 anos de idade sendo esta a de maior risco ao contágio de ISTs. Há inúmeros fatores de riscos que determinam a maior incidência de contágio em uma determinada população, como a falta de proteção nas relações devido ao início precoce da vida sexual. Por volta dos 12 a 17 anos de idade, cerca de quatro milhões de jovens, iniciam sua vida sexual, podendo ser portadores e transmissores de várias infecções (AMORAS et al., 2015). Essa é uma idade que muitos jovens se sentem atraídos instintivamente a experimentarem novas sensações e prazeres, o que os tornam mais vulneráveis. É uma fase de muito conflito e de descobertas, de conhecer a sexualidade, seu corpo e o prazer e de mudanças no corpo e na mente devido a fatores hormonais (AMORAS et al., 2015; SILVA, 2015). Há também o incentivo da mídia, que pode estimular a possibilidade de conquistar diversos parceiros sexuais transformando esse início da etapa sexual bem intenso e perigoso (MACINTYRE et al., 2015).

Há uma relação diretamente proporcional entre a falta de conhecimento a respeito do tema com o aumento das taxas de gravidez na adolescência e do número de ISTs (KRABBE et al., 2016). Em geral, há um tabu envolvendo questões sobre essa problemática e as conversas entre pais e filhos não são tão comuns, então muitos adolescentes buscam a escola ou outros indivíduos como fonte de conhecimento sobre o tema. Normalmente as informações sobre sexualidade são trabalhadas por professores de Ciências/Biologia ainda que tratem do tema com certa dificuldade e insegurança utilizando quase que exclusivamente os livros didáticos e se restringindo apenas a questões fisiológicas e anatômicas, ficando de fora pontos cruciais para a promoção da saúde humana (SILVA, 2015). Também ficando a cargo do docente promover e desenvolver um ambiente favorável ao processo de ensinoaprendizagem visando estimular seus alunos a construírem conhecimento suficiente na promoção da qualidade de vida. A falta de um local adequado para o debate sobre 
questões ligadas ao sexo juntamente com a carência de conhecimentos legítimos torna os adolescentes mais propícios às infecções. Todo esse quadro leva a necessidade de ações no âmbito da educação escolar visando a prevenção dessas doenças (MOURA et al., 2015).

Uma vez que o ensino de Ciências/Biologia, muitas vezes, é trabalhado por métodos mais tradicional, teórico e pouco contextualizado (ZAPPE et al., 2018), uma das estratégias bem-sucedida nessa área é o uso da sequência didática (SD). A SD pode ser definida como um conjunto de aulas planejadas previamente envolvendo os conceitos previstos na pesquisa didática com o intuito de melhorar o processo ensino-aprendizado. Quando essa SD é realizada em parceria com a comunidade escolar e de forma lúdica há mais chances de atingir o sucesso no ensino de ciências e, consequentemente, reduzir as lacunas deixadas pelos livros didáticos (JOHAN et al., 2014). A SD pode apresentar ferramentas para que o discente consiga utilizá-las de acordo com sua realidade. Assim, o estudo de Ciências pode ser mais proveitoso e pautado no processo da investigação, o que proporciona mais autonomia e empoderamento ao aluno e mais envolvimento no seu processo de aprendizagem. Uma vez que a SD é um instrumento adaptável aos objetivos apresentados pelo docente com a finalidade de promover aos seus alunos um aprendizado mais contextualizado, sistematizado e dinâmico (OLIVEIRA, 2013). Neste contexto, o objetivo do estudo foi propor e analisar como uma sequência didática pode contribuir no processo de ensino-aprendizagem sobre a temática ISTs.

\section{MATERIAIS E MÉTODOS}

\subsection{Caracterização da pesquisa}

Esse estudo é caracterizado como uma pesquisa documental qualitativa com aplicação de questionários para alunos e professores e a elaboração de uma sequência didática utilizando a produção de um livro paradidático como método avaliativo. Este estudo foi realizado de agosto a outubro de 2018 na Escola Estadual 
de Referência em Ensino Médio Guiomar Krause Gonçalves, localizada na cidade de Vitória de Santo Antão-PE, com os estudantes das da turma do $1^{\circ}$ ano médio $B .0$ presente projeto foi devidamente aprovado no Comitê de Ética em Pesquisa da Universidade Federal de Pernambuco (CAE: 87012218.2.0000.5208).

\subsection{Procedimentos para coleta}

\subsubsection{Construção do corpus empírico a partir dos questionários}

Um bimestre antes do conteúdo ISTs ser ministrado em sala de aula, um questionário pré-teste composto por 20 questões objetivas e 2 discursivas foi distribuído para cada aluno responder para avaliar o conhecimento prévio do aluno sobre ISTs. Simultaneamente foi entregue ao professor da turma, responsável por aplicar a sequência didática, um questionário com perguntas também objetivas e subjetivas sobre ISTs. A sequência didática foi desenvolvida como estratégia de ensino-aprendizagem. Ao término das aulas foi aplicado um segundo questionário, de caráter avaliativo, para compreender quais saberes a sequência didática favoreceu.

Os dados obtidos das respostas dos questionários aplicados aos alunos foram avaliados através de métodos comparativos dos seus conhecimentos antes e após a abordagem do tema. Os dados obtidos das respostas dos questionários aplicados a professor foram avaliados através da comparação destas respostas com a conduta no seu processo pedagógico, em uma perspectiva de reflexão sobre o ensino-aprendizagem.

\subsubsection{Construção do corpus empírico a partir da sequência didática}

Este estudo propõe o desenvolvimento, aplicação e avaliação de uma sequência didática composta por atividades pedagógicas sobre "Infecções Sexualmente Transmissíveis". A sequência foi composta por cinco momentos, sendo atribuídas duas aulas em cada momento, totalizando dez aulas, conforme descrita no Quadro 1. 
Quadro 1 - Sequência didática para o ensino de ISTs

\begin{tabular}{|c|c|c|c|}
\hline Momento & Aula & Objetivos & Atividades desenvolvidas \\
\hline \multirow[t]{2}{*}{01} & $1^{\text {a }}$ & $\begin{array}{l}\text { - Apresentar o conteúdo de forma } \\
\text { lúdica. }\end{array}$ & - Utilização do Jogo das ISTs. \\
\hline & $2^{a}$ & $\begin{array}{l}\text { - Relacionar as questões tratadas no } \\
\text { jogo ao cotidiano do aluno. } \\
\text { - Estimular à pesquisa. } \\
\text { - Associar teoria à prática. }\end{array}$ & $\begin{array}{l}\text { - Roda de conversa. } \\
\text { - Textos sobre ISTs. } \\
\text { - Estudos de casos clínicos. }\end{array}$ \\
\hline \multirow[t]{2}{*}{02} & $3^{a}$ & $\begin{array}{l}\text { - Contextualizar o assunto a casos } \\
\text { frequentes de ISTs. } \\
\text { - Desenvolver o protagonismo do } \\
\text { aluno no processo da aprendizagem. }\end{array}$ & $\begin{array}{c}\text { - Apresentação dos estudos de casos } \\
\text { clínicos. }\end{array}$ \\
\hline & $4^{a}$ & $\begin{array}{c}\text { - Consolidar o conhecimento acerca do } \\
\text { tema ISTs. } \\
\text { - Incentivar à pesquisa. } \\
\text { - Explorar o conhecimento sobre } \\
\text { paradidáticos. }\end{array}$ & $\begin{array}{l}\text { - Aula expositiva e dialogada. } \\
\text { - Pesquisa sobre paradidáticos. }\end{array}$ \\
\hline \multirow[t]{2}{*}{03} & $5^{a}$ & $\begin{array}{l}\text { - Formar equipes para o } \\
\text { desenvolvimento de atividades. } \\
\text { - Revisar o conteúdo para melhor } \\
\text { aproveitamento das atividades. }\end{array}$ & $\begin{array}{l}\text { - Sorteio dos grupos de } \\
\text { microrganismos para cada equipe. } \\
\text { - Distribuição e leitura de textos } \\
\text { resumos sobre cada grupo de } \\
\text { microrganismos. }\end{array}$ \\
\hline & $6^{a}$ & $\begin{array}{l}\text { - Estimular a pesquisa. } \\
\text { - Desenvolver o protagonismo do } \\
\text { aluno no processo da aprendizagem. } \\
\text { - Auxiliar na produção do paradidático. }\end{array}$ & $\begin{array}{c}\text { - Realização de pesquisas sobre } \\
\text { microrganismos para produção do } \\
\text { paradidático. }\end{array}$ \\
\hline \multirow[t]{2}{*}{04} & $7^{a}$ & $\begin{array}{c}\text { - Promover a interdisciplinaridade. } \\
\text { - Ampliar a compreensão com relação } \\
\text { a paradidáticos. }\end{array}$ & $\begin{array}{c}\text { - Aula com a professora de } \\
\text { Português sobre produção de } \\
\text { paradidáticos. }\end{array}$ \\
\hline & $8^{a}$ & - Compor os paradidáticos. & $\begin{array}{l}\text { - Ajustes e organização do } \\
\text { paradidático. }\end{array}$ \\
\hline 05 & $\begin{array}{c}9^{a} \\
10^{a}\end{array}$ & $\begin{array}{c}\text { - Socializar o conhecimento } \\
\text { apreendido ao longo da sequência } \\
\text { didática. }\end{array}$ & $\begin{array}{l}\text { - Momento de autógrafos: exposição } \\
\text { e apresentação dos paradidáticos. }\end{array}$ \\
\hline
\end{tabular}


Antes da execução da sequência didática houve a aplicação do seguinte questionário pré-teste para fins de análise e planejamento da SD.

1) Uma maneira de se proteger de Infecções Sexualmente Transmissíveis (ISTs) é ter relações sexuais apenas com pessoas que aparentam ter boa saúde?

( ) $\operatorname{SIM}($ ) NÃO

2) A pílula anticoncepcional, além de evitar a gravidez, também previne as ISTs?

( ) SIM ( ) NÃO

3) Feridas, corrimento e verrugas no pênis e na vagina são sempre sinais de ISTs?

( ) SIM ( ) NÃO

4) É possível contrair HIV ao usar o mesmo banheiro que alguém que tem HIV/AIDS também usou?

( ) SIM ( ) NÃO

5) As ISTs também podem ser transmitidas através de picadas de insetos como pernilongos?

( ) SIM ( ) NÃO

6) É possível o contágio de uma IST entre duas pessoas que não a possuam?

( ) SIM ( ) NÃO

7) Uma pessoa pode contrair mais de uma IST?

( ) SIM ( ) NÃO

8) Um indivíduo com IST pode se curar sozinho?

( ) SIM ( ) NÃO

9) HIV e AIDS são as mesmas coisas?

( ) SIM ( ) NÃO

10) As ISTs são passadas apenas pelo sexo?

( ) SIM ( ) NÃO

11) Uma pessoa com HIV pode frequentar a escola?

( ) SIM ( ) NÃO

12) A AIDS pode ser transmitida através do beijo?

( ) SIM ( ) NÃO 
13) O sexo oral é seguro por não apresentar perigo de contrair ISTs?

$$
\text { ( ) } \operatorname{SIM}(\quad) \text { NÃO }
$$

14) Quais doenças abaixo são exemplos de ISTs?
( ) AIDS
( ) Amebíase
( ) Candidíase
( ) Cólera
( ) Coqueluche
( ) Dengue
( ) Doença de Chagas
( ) Febre Amarela ( ) Giardíase
( ) Gonorreia
( ) Hanseníase
( ) Hepatite
( ) Herpes
( ) Rubéola
( ) Sarampo
( ) Papiloma Vírus Humano (HPV)
( ) Leptospirose
( ) Meningites
( ) Poliomielite ( ) Raiva
( ) Sífilis
( ) Teníase
( ) Tuberculose

15) Uma criança pode nascer com alguma IST?

( ) $\operatorname{SIM}(\quad) N \tilde{O} O$

16) Usar alicates de unha, tesouras e lâminas de terceiros não apresenta riscos de contaminação de ISTs?

( ) VERDADE ( ) MENTIRA

17) Há cura para qualquer tipo de IST?

$$
\text { ( ) } \operatorname{SIM}(\quad) \text { NÃO }
$$

18) Num abraço ou num aperto de mão há sempre o risco de contrair uma IST?

$$
\text { ( ) } \operatorname{SIM}(\quad) \text { NÃO }
$$

19) Você já participou de algum projeto escolar em parceria com a UFPE/CAV sobre as ISTs?

$$
\text { ( ) } \operatorname{SIM}(\quad) \text { NÃO }
$$

20) O compartilhamento de objetos para o uso de drogas, como seringas e agulhas, pode ser um meio para adquirir ISTs?

$$
\text { ( ) } \operatorname{SIM}(\quad) \text { NÃO }
$$

21) Uma pessoa percebe um corrimento esverdeado saindo do pênis/vagina frequentemente e ainda sente ardência ao urinar. Que atitude esse indivíduo deve tomar?

22) O que uma pessoa deve fazer para saber se possui alguma IST? E caso a tenha, o que deve fazer? 
Iniciando o $1^{\circ}$ momento foi realizado um jogo de tabuleiro intitulado "O Jogo das ISTs", onde os estudantes formaram quatro equipes para disputar entre si. Esse jogo apresentou questões de verdadeiro e falso relacionadas a problemas cotidianos e frequentes advindos de ISTs, como contágio, doença, prevenção e tratamento. Posteriormente, foi organizado um círculo para que o professor possa debater e relacionar os pontos trabalhados no jogo aos casos vividos e/ou observados pelos alunos, abrindo uma conversa a fim de contextualizar o assunto. O primeiro momento foi finalizado com um estudo de caso, onde foi entregue a cada equipe um caso clínico contendo informações sobre algumas ISTs e cada equipe pesquisou e apresentou no momento seguinte a possível IST responsável pelos casos clínicos.

O $2^{\circ}$ momento iniciou com uma apresentação da atividade proposta no momento anterior e um debate em torno dos estudos de casos clínicos. Posteriormente foi explanado o conteúdo teórico sobre ISTs através de uma aula expositiva e dialogada, com o intuito de tirar possíveis dúvidas surgidas no decorrer dessa etapa. Encerrando esse momento, foi proposta aos estudantes uma pesquisa sobre paradidáticos onde foram contempladas questões como função, estrutura, diagramação, formatação, produção, dentre outros.

Para o $3^{\circ}$ momento, o professor sorteou os temas dos grupos de microrganismos para cada equipe e entregou a cada equipe um texto com um resumo sobre seu grupo de microrganismo para eventuais dúvidas sobre o assunto. Em seguida foi solicitado aos alunos que pesquisassem e desenvolvessem uma história de acordo com a temática sugerida, utilizando o laboratório de informática, a biblioteca e/ou o celular para fazer pesquisas.

No $4^{\circ}$ momento foi realizada uma atividade interdisciplinar na qual os alunos tiveram a colaboração da professora de Português para orientá-los com relação à estruturação e a construção do paradidático, ajudando as equipes a transformarem sua história para o formato de um paradidático.

O $5^{\circ}$ momento correspondeu a tarde de autógrafos com a exposição e distribuição dos paradidáticos. 
Após a aplicação da SD foi aplicado outro questionário como um dos métodos avaliativos:

1- Você acredita que a sequência didática favoreceu seu aprendizado em relação a uma aula mais tradicional?

( ) Não ( ) Sim, um pouco ( ) Sim, muito

2- Qual grau de importância você avalia o aprendizado de IST? Sendo 0 correspondente à não ter nenhuma importância e 5 o de ser extremamente importante.

( ) 0

$$
\text { ( } \left.\begin{array}{lll} 
& 1 & (
\end{array}\right)
$$$$
\text { ( ) } 3
$$$$
\text { ( ) } 4
$$$$
\text { ( ) } 5
$$

3- Como você avalia seu grau de participação durante toda a sequência didática? Sendo 0 correspondente à não ter participado e 5 o de participado com bastante empenho.

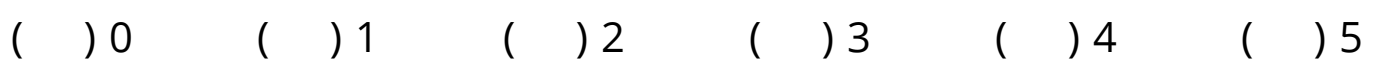

4- Você acredita ter se tornado uma pessoa mais cautelosa após as aulas sobre ISTs?

( ) Não ( ) Sim, um pouco ( ) Sim, muito

5- Seu interesse sobre o assunto mudou após a sequência didática?

( ) Não ( ) Sim, diminuiu ( ) Sim, aumentou

6- Você debateu sobre esse assunto fora de sala de aula (com seus amigos, parentes, vizinhos) após o início dessas aulas?

( ) Não ( ) Sim

7- Um indivíduo que apresenta um enfraquecimento do sistema imunológico e consequentemente uma maior vulnerabilidade para aparecimentos de doenças oportunistas pode estar com qual tipo de IST?

( ) Gonorreia ( ) HPV ( ) Sífilis ( ) AIDS ( ) Tricomoníase

8- Após poucos dias de uma relação sexual desprotegida, João percebeu o aparecimento de pequenas feridas em seu pênis e também a presença de uma íngua em sua virilha. Esse problema não progrediu e depois de uns 10 dias esses sintomas desapareceram. Passada algumas semanas ele começou a notar algumas manchas em seu corpo, coceira e ínguas no pescoço e nas axilas. Outra vez os sintomas 
desapareceram. Mais de uma década depois dos primeiros sintomas aparecerem, João começou a apresentar convulsões, rigidez no pescoço e problemas cardíacos. Infelizmente veio a óbito por falta de tratamento. Qual provável IST tinha essa pessoa?

( ) Gonorreia ( ) HPV ( ) Sífilis ( ) AIDS ( )Tricomoníase

9- Maria teve sua filha sem realizar nenhum exame de pré-natal durante toda a gestação. Por volta do terceiro dia do nascimento o bebê apresentou sintomas parecidos com conjuntivite: pálpebras inchadas e olhos vermelhos. A partir de exames realizados na mãe e no recém-nascido foi descoberto que elas possuem uma das seguintes ISTs.

( ) Gonorreia ( ) HPV ( ) Sífilis ( ) AIDS ( ) Tricomoníase

10- Por meio de exames passados por seu ginecologista, Paula descobriu que estava com câncer no colo do útero. O médico a perguntou se tinha tomado um tipo de vacina quando era mais nova, e a resposta foi que não. Ele a informou que essa vacina poderia ter evitado esse problema em Paula, mas que agora o melhor seria um tratamento específico para essa enfermidade. Que IST essa mulher pôde ter contraído?

( ) Gonorreia ( ) HPV ( ) Sífilis ( ) AIDS ( ) Tricomoníase

\section{RESULTADOS E DISCUSSÃO}

No mundo contemporâneo a quantidade de informações apresentadas diariamente pelos mais diferentes meios, sugere uma falsa sensação de empoderamento do saber científico. Porém muitas vezes esse conhecimento é superficial e não favorece na formação e vivência da sexualidade do indivíduo por tentar apresentar explicações prontas sobre os diversos temas (EW et al., 2017). Apesar da globalização e do alto nível tecnológico atual, e, além das políticas públicas voltadas à saúde dos estudantes na fase da adolescência, as informações sobre sexualidade normalmente são confusas, caracterizando-se como um transtorno em ascensão, preferencialmente em rapazes (OLIVEIRA et al., 2017). Portanto, este trabalho visa desenvolver o aspecto investigativo do aluno com a finalidade da 
promoção do saber de rigor científico, favorecendo a conscientização e ajuste de conduta frente às questões ligadas as ISTs, utilizando-se de várias etapas na construção do conhecimento por meio da aplicação de uma sequência didática (SD). Essa estratégia de ensino pode contribuir para que a educação seja capaz de gerar consciência baseada na busca por autonomia, responsabilidade, e que seja livre de tabus e preconceitos, e compreendida como elemento fundamental para a vida (ALTMANN et al., 2009).

A SD pode utilizar de várias ferramentas para um melhor aprendizado dos alunos (MATOS, 1971). A SD elaborada nesse trabalho foi realizada a partir de atividades diversas como jogo de tabuleiro, roda de conversa, leitura de imagem, utilização de textos de divulgação científica, aula expositiva e dialogada, além do uso de questionários e a produção de um livro paradidático.

O jogo, parte integrante da sequência didática aplicada, é mais um instrumento facilitador da aprendizagem, pois essa atividade oportuniza o aumento das competências e habilidades dos indivíduos (ZUANON et al., 2011). Sendo esse exercício, de caráter lúdico, ele é um excelente recurso didático para firmar conhecimentos trabalhados nas aulas de biologia e proporciona um espaço motivador de aprendizagem (SAVI et al., 2008). Nessa atividade foi observada a participação quase unânime dos estudantes, através da interação e estímulo para responder os questionamentos propostos pelo Jogo das ISTs (Figura 1).

Figura 1 - Jogo das Infecções Sexualmente Transmissíveis
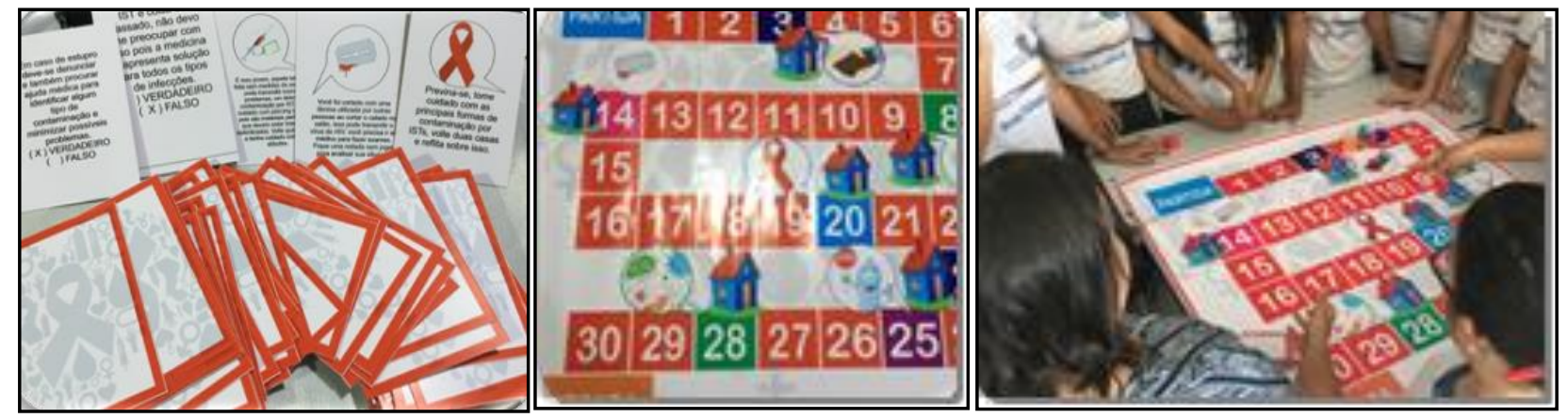

Fonte: Autores (2018) 
A maioria das perguntas foi acertada pelas equipes participantes e após cada resposta a professora também discutia sobre o tema, produzindo uma atividade mais contextualizada e interessante Ao término do jogo foi feito um ranking com as colocações de cada equipe (do $1^{\circ}$ ao $4^{\circ}$ lugar), finalizando essa primeira etapa com bastante entusiasmo por parte dos participantes e da professora. Essa atividade foi de extrema importância para introduzir o tema de forma que eles pudessem participar e empregar seus saberes prévios como proposta de trabalho em equipe. A observação do docente nesse momento foi de grande valor, não apenas para conduzir a atividade, mas também para analisar o grau de conhecimento da turma a partir de uma sondagem em cada ação ocorrida no jogo de tabuleiro proposto pela sequência didática.

Os jovens podem ser influenciados positivamente, minimizando comportamentos de risco, quando recebem informações coesas sobre o tema (FREITAS, 2012). De acordo com Helena Altmann (2007), é direito do adolescente o alcance de informações em educação sexual, assim como o conhecimento sobre métodos contraceptivos e de prevenção contra ISTs. Contudo eles quase não dispõem de oportunidades onde possam discutir sobre o tema, recebendo informações superficiais, distorcidas e pouco trabalhadas devido ao tabu e ao preconceito que ainda predomina em torno do objeto, o que torna uma intervenção escolar uma proposta relevante. Para EW (2017), a utilização de uma roda de conversa proporciona aos jovens a exposição de ideias e percepções que podem promover reflexões quanto a sua perspectiva conceitual, possibilitando a tolerância sexual. Na prática, observou-se que a maior parte dos alunos se sentiu confortável ao terem que conversar sobre as ISTs na roda de conversa conduzida pela professora na sala de aula (Figura 2), eles discutiram com certa naturalidade, levantando vários questionamentos sobre o tema. Inicialmente, alguns poucos alunos se mostraram tímidos para realizar perguntas ou sugerir respostas, mas ao longo do período proposto para essa atividade percebeu-se um maior interesse deles em participar de forma mais ativa. 
Ausubel (1983) declarou que é preciso determinar o conhecimento que o aluno já carrega para, a partir daí, aprimorar os processos de ensino e aprendizagem. Além da sondagem no primeiro momento da sequência didática, observada com o jogo de tabuleiro sobre as ISTs e na roda de conversa, também houve a aplicação de um questionário (Figura 3), dois meses antes do início da aplicação da SD. Estiveram presentes no dia da aplicação do questionário 21 alunos e todos eles responderam o questionário espontaneamente. Dessa forma, houve tempo necessário para analisar os dados obtidos para que a SD fosse planejada a partir do grau de conhecimento dos alunos. Essa personalização aumenta as chances de obter resultados mais satisfatórios, pois a sondagem favorece o trabalho do professor possibilitando a adaptação do conteúdo às necessidades dos estudantes (PAIVA et al., 2005).

Figura 2 - Roda de conversa sobre Infecções Sexualmente Transmissíveis

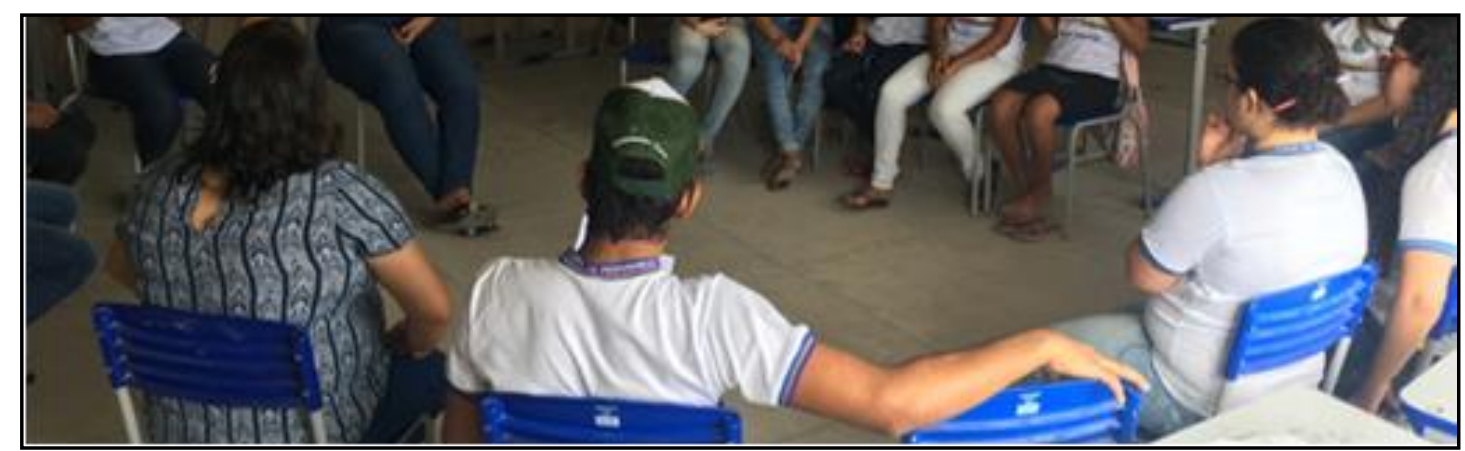

Fonte: Autores (2018)

Figura 3 - Aplicação do questionário pré-teste

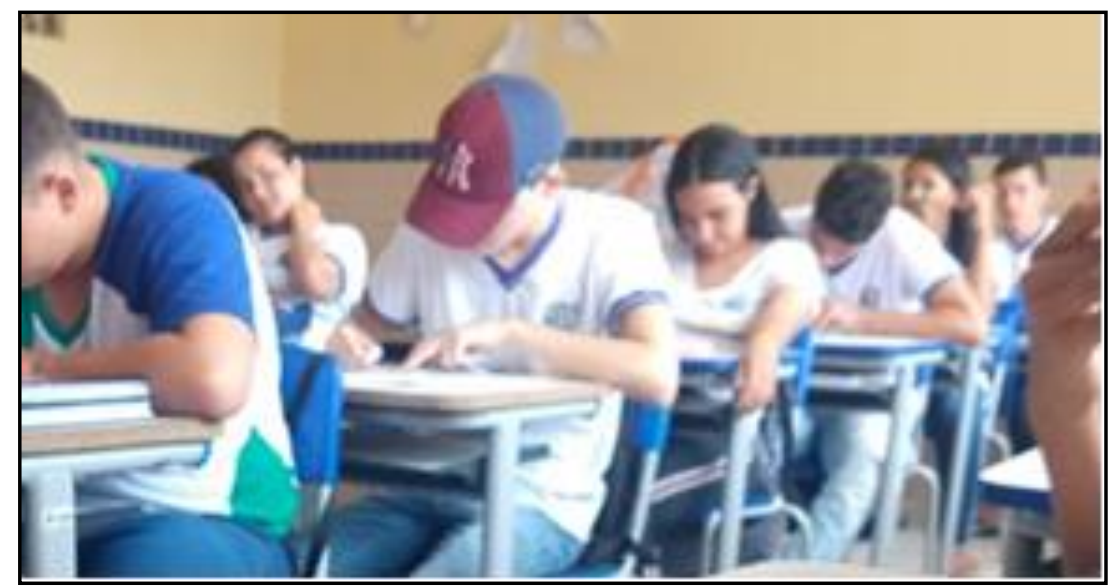

Fonte: Autores (2018) 
A partir da correção e análise do questionário pré-teste, foi observado que todos os alunos têm a convicção da possibilidade de adquirir mais de um tipo de IST sem a devida proteção, 95\% afirmaram que é necessário tratamento para a cura ou manutenção da saúde, 67\% afirmaram que há possibilidade da transmissão dessas infecções por meio do uso de objetos perfurantes e aproximadamente 57\% souberam identificar as principais doenças causadas por ISTs. Na parte objetiva do questionário, a turma obteve uma nota aproximada de 6,3 (de 0 a 10) e os acertos estão apresentados na tabela 1.

Por outro lado, o quantitativo de estudantes que relacionam características semelhantes entre os sintomas de ISTs e outras doenças/infecções é muito baixo (14\%), não permitindo compreender a ampla gama de agentes infectantes e seus sintomas fora do contexto das ISTs. A maioria não sabia da existência de diferença entre o HIV e AIDS (67\%), além de acreditarem que as ISTs são transmitidas exclusivamente pelo sexo (57\%) e que a AIDS pode ser propagada também pelo beijo (52\%).

Já na parte discursiva do questionário, percebeu-se que $90 \%$ dos alunos apresentam a consciência da procura médica diante de uma possível situação de IST, assim como da importância dos exames clínicos para detectar algum tipo de infecção. Essa pesquisa prévia é de suma importância, pois trabalhar a partir do conhecimento já existente valoriza o educando e maximiza seu processo de ensino e aprendizagem (TEIXEIRA et al., 2016).

O professor tem o papel de mediar e desenvolver situações de aprendizagem para o aluno de acordo (SOUZA et al., 2015), assim faz-se necessário conhecer sua metodologia e visão sobre o tema. Neste sentido, foi entregue ao docente, no período que antecedeu a aplicação da SD, um questionário para identificar o perfil do profissional (Figura 4). Com a análise do questionário foi possível identificar algumas particularidades que favoreceram a escolha desse docente para realizar essa atividade. O professor que aplicou a SD acredita que o tema IST é um tema relevante da Biologia e normalmente dedica mais atenção para desenvolver essas aulas. O professor informou ainda que percebe uma maior curiosidade e participação dos alunos quando esse assunto é apresentado, e que isso é positivo 
para o desenvolvimento das aulas. Ele enfatizou também que nota com frequência a timidez de alguns estudantes diante dessas aulas, mas que isso não atrapalha sua didática. Ele costuma utilizar o livro didático para abordar as ISTs, mas esses livros muitas vezes trazem a temática de forma insuficiente para o entendimento básico do aluno, por esse motivo usa também textos e imagens para auxiliar suas aulas. Por fim relatou que se sente à vontade para tratar desse assunto e que é uma maneira de contribuir para a saúde da comunidade escolar.

Tabela 1: Resultado das respostas das questões objetivas do questionário pré-teste

\begin{tabular}{cccc}
\hline Questão & Acertos & Erros & Não responderam \\
\hline 1 & 10 & 11 & - \\
2 & 16 & 04 & 01 \\
3 & 02 & 18 & 01 \\
4 & 13 & 8 & - \\
5 & 11 & 10 & - \\
6 & 14 & 07 & - \\
7 & 21 & - & - \\
8 & 20 & 01 & - \\
9 & 07 & 14 & - \\
10 & 09 & 12 & 01 \\
11 & 17 & 04 & 01 \\
12 & 09 & 11 & - \\
13 & 17 & 03 & 04 \\
14 & 12 & 9 & 01 \\
15 & 16 & 01 & 02 \\
16 & 14 & 06 & - \\
17 & 10 & 09 & - \\
18 & 20 & - & - \\
20 & 21 & - & - \\
\hline
\end{tabular}


Outro recurso didático utilizado nessa SD foi a aplicação e discussão de Texto de Divulgação Científica (TDC). Segundo Silva et al (2006) há três principais fatores que favorecem o uso de TDC, sua acessibilidade e facilidade de manuseio, além da linguagem de fácil entendimento; sua contribuição na formação de estudantes mais bem informados, reflexivos e questionadores; e a possibilidade de fazer os alunos perceberem a importância do uso de textos científicos para a leitura, análise, reflexão e conclusão de seus questionamentos.

Por meio da leitura realizada de um TDC em sala de aula (Figura 5), a professora percebeu que certos pontos apresentados no texto despertaram a curiosidade de alguns alunos, pois o TDC escolhido foi atual e direcionado a adolescentes em período escolar. No momento dessa leitura, muitos alunos conversaram entre si sobre informações que eles acharam interessantes. Ao retorno do grande grupo a docente direcionou as questões realizadas pelos alunos de acordo com a ordem com que cada aluno se dispunha no grande círculo. Foi uma etapa de intenso diálogo onde as dúvidas abordadas eram inseridas em contextos e explanadas já com uso de determinados conceitos científicos para tentar introduzi-los ao conteúdo proposto. De acordo com Ferreira et al. (2012) os TDC podem levantar novas questões, além das questões já abordadas no livro didático, e expandir a visão de ciência e do que está ao redor dos envolvidos na construção do conhecimento científico, por meio de novas estratégias e métodos de ensino na atualidade.

Figura 4 - Aplicação de um questionário para identificar o perfil do profissional

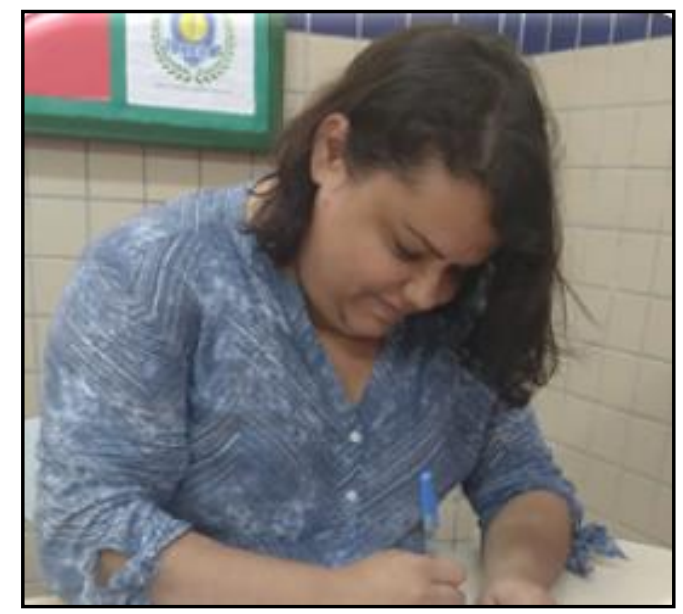

Fonte: Autores (2018) 
Figura 5 - Leitura de Texto de Divulgação Científica

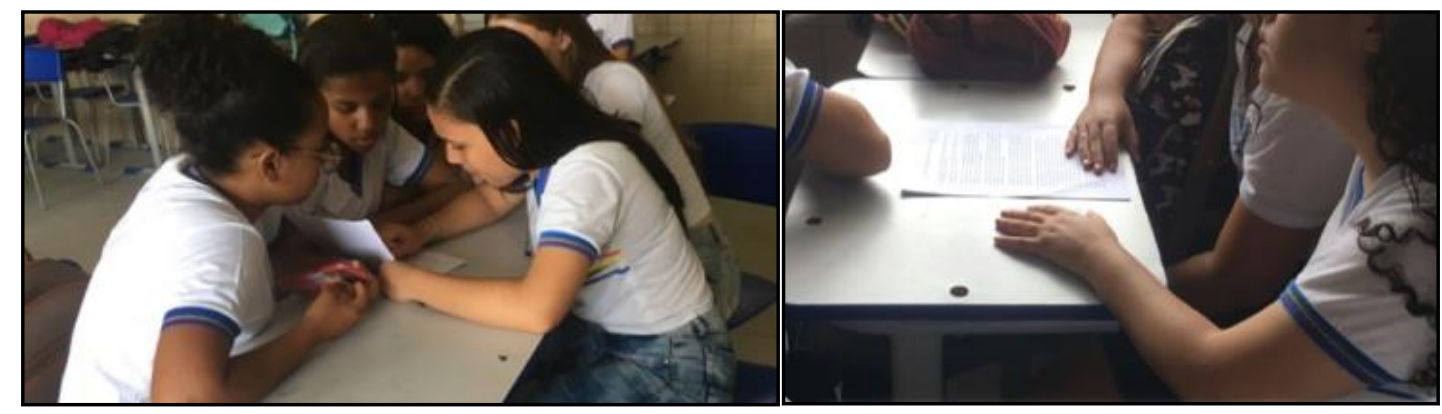

Fonte: Autores (2018)

As aulas de caráter investigativo auxiliam os professores a tornarem a sala de aula um ambiente mais ativo onde envolvam os alunos a buscarem por respostas (ZAGO et al., 2007). Assim sendo, por meio da distribuição de casos clínicos a cada grupo de estudantes (Figura 6), eles desenvolveram a pesquisa no intuito de identificar a IST causadora de determinados sintomas apresentados em cada caso. Assim, contatou-se a significância dessa atividade investigativa, quando os alunos se viram incumbidos de mostrar ao grande grupo uma resolução para o seu problema, onde cada um se encontrava na função de buscar uma solução viável e justificável. Outras atividades investigativas também foram aplicadas, como o uso de imagens de microrganismos infectantes e da manifestação de suas respectivas doenças, associadas a perguntas que levaram muitos alunos a tentar responder com o conhecimento previamente adquirido, ou ainda utilizando o livro didático e aparelhos celulares para buscar informações no intuito de responder sobre as questões propostas pela docente.

Figura 6 - Atividade investigativa de estudo de casos clínicos

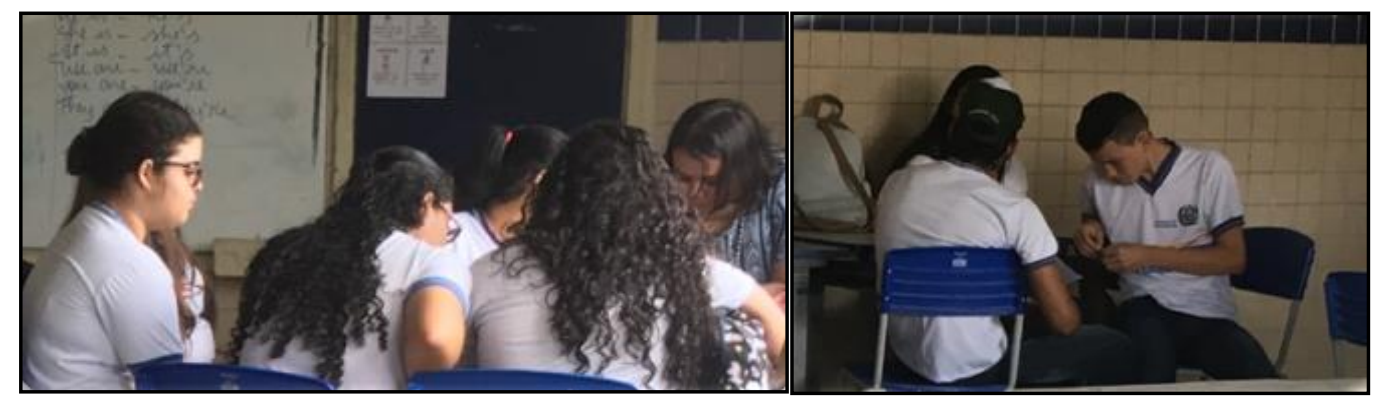

Fonte: Autores (2018) 
Outro elemento dessa sequência foram as aulas expositivas. Segundo Alves (2007) deve haver um equilíbrio entre as aulas expositivas e as práticas, pois apenas um tipo de aula torna-a incompatível com uma aprendizagem mais eficaz. Acreditando que as aulas expositivas têm o intuito de informar, requerendo grande atenção por parte dos alunos, surge como mais um importante elemento executado na presente SD. A partir dessas aulas os alunos puderam relacionar todo o conhecimento abordado nas etapas anteriores e relaciona-los com a parte teórica da disciplina. Um dos aspectos interessantes que se observou nessa etapa, foi à afinidade que alguns alunos apresentaram com o conteúdo, entendendo que o processo anterior foi de fundamental importância na sua preparação para esse momento, e servindo como um indicativo de que a SD estava sendo desenvolvida de forma satisfatória até o presente estágio. Outro episódio curioso notado foi o uso de aparelhos eletrônicos simultaneamente à aula por alguns estudantes onde os mesmos utilizaram desse meio de pesquisa como método complementar de estudo discorrendo de novas questões o que tornou a aula dinâmica e com conhecimentos bilaterais. De acordo com a docente, houve um maior volume de questionamentos nessa aula expositiva que nas ministradas por ela sobre outros temas. Vale salientar que essa aula foi apresentada por meio de slides ilustrados e didáticos, além da boa desenvoltura da professora em ministrar a aula (Figura 7).

Figura 7 - Aulas expositivas sobre Infecções Sexualmente transmissíveis

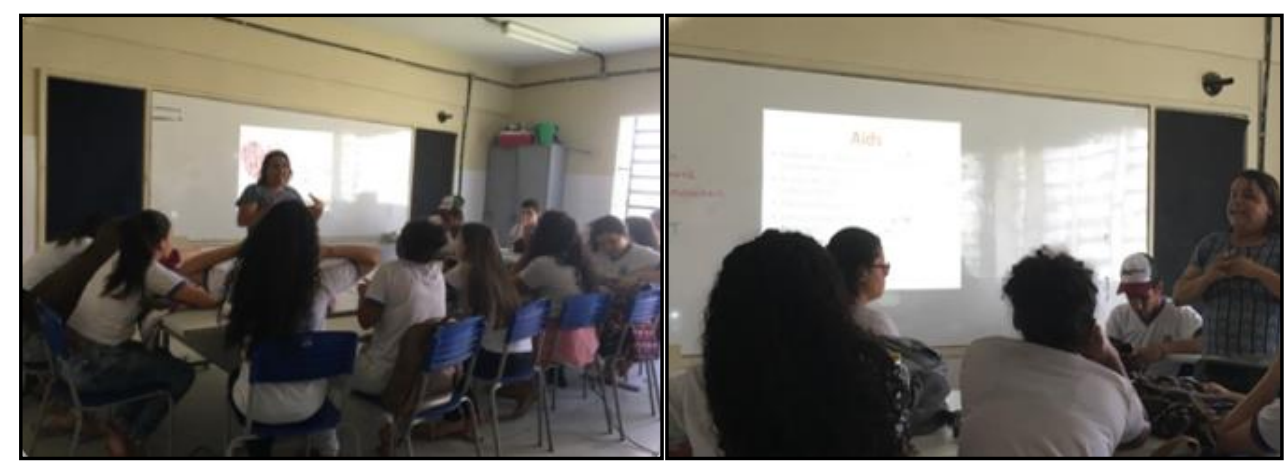

Fonte: Autores (2018)

A SD teve como desfecho a elaboração de um livro paradidático para ser apresentado e compartilhado para os demais alunos do $1^{\circ}$ ano do ensino médio da 
mesma escola. O processo de ensino e aprendizagem proporcionado pela SD, associada a utilização do conhecimento adquirido mais o método investigativo de pesquisa para que os grupos, previamente formados em sala de aula, contribuíram para a elaboração desse livro paradidático. De acordo com Júnior et al (2018), sabese que esse tipo de material é um recurso que complementa outros instrumentos de aprendizagem, são compostos de informações objetivas, ilustrativa e didática. Afirma também que esse recurso permite trabalhar de forma interdisciplinar e provoca a imersão do aluno nesse no assunto abordado.

De início, a maioria dos alunos ficou insegura sobre essa produção. Antes mesmo dessa proposta, a professora introduziu esse tópico por meio de pesquisa investigativa no intuito de diminuir as prováveis dúvidas que pudessem surgir com essa atividade. Houve um momento interdisciplinar muito importante quando a professora de português foi convidada a ministrar uma aula sobre paradidático, expondo com isso uma breve introdução, objetivos, técnicas e várias outras características sobre os paradidáticos. Dessa forma os estudantes tiveram oportunidade de discutir e tirar o maior número de dúvidas possíveis sobre a ação. Mesmo após a aula interdisciplinar, a professora se disponibilizou a acompanhar o desenvolvimento dos paradidáticos dos alunos assim que surgissem mais dúvidas. Durante o tempo proposto para esse exercício, os discentes deveriam mostrar regularmente o progresso de seus trabalhos a fim de estimulá-los a desenvolver a produção.

Dos quatro grupos formados, dois apresentaram resultados satisfatórios, concluindo suas tarefas em tempo determinado. As outras duas equipes tiveram um desempenho aquém do esperado, não chegando a concluir seus trabalhos. Contudo das duas equipes que tiveram seus paradidáticos finalizados, um grupo apresentou resultado acima do previsto, fato esse que motivou a impressão gráfica do mesmo.

Após esse processo o livro foi reestruturado pelo grupo de alunos, revisado e enviado para impressão em gráfica. Em seguida ocorreu o momento de autógrafos aos demais alunos das outras turmas do $1^{\circ}$ ano do ensino médio (Figura 8). Essa etapa foi de muita alegria e foi possível observar o entusiasmo dos integrantes da 
equipe em ter seu trabalho publicado e distribuído para outros alunos. A cada grupo de estudantes que entravam na biblioteca da escola, os envolvidos nesse livro paradidático autografavam, explicavam sobre a produção e verbalizavam sobre sua experiência em relação a esse processo. Nesta atividade ficou nítido o alto grau de compromisso das equipes nas etapas da construção de livros paradidáticos, principalmente naqueles alunos que aceitaram esse desafio. Desta forma, as estratégias de ensino e aprendizagem, como por exemplo, a elaboração de um livro paradidático, melhoram o aprendizado (FERNANDES et al., 2015).

Figura 8 - Tarde de autógrafos dos livros paradidáticos sobre Infecções Sexualmente Transmissíveis

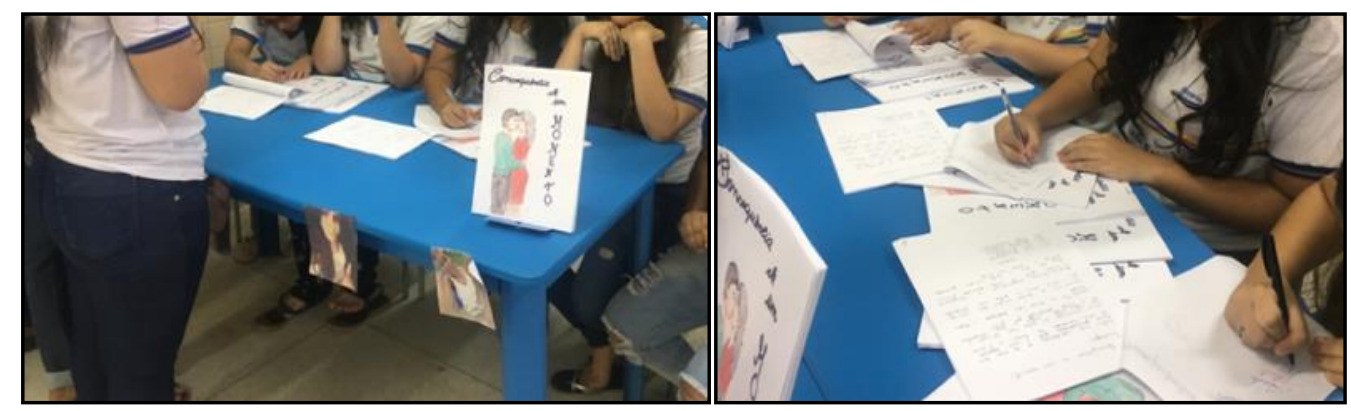

Fonte: Autores (2018)

Para qualificar e quantificar todo esse processo pedagógico foi realizada a aplicação de um segundo questionário aos mesmos 21 alunos. A maioria dos alunos destacou que o uso da SD foi mais efetivo no processo de aprendizagem (92\%) comparado a uma aula tradicional. Dezesseis alunos informaram que a SD favoreceu muito o aprendizado (77\%), 3 alunos informaram que a SD favoreceu um pouco o aprendizado (15\%) e 2 alunos relataram que a SD não auxiliou no aprendizado (8\%). Dezessete estudantes acham importante o aprendizado de ISTs (84\%), 2 consideram o tema IST com uma importância mediana (8\%) e 2 alunos não acham o tema IST importante (8\%). Quanto a auto avaliação sobre a participação nas atividades, a maioria dos alunos consideram alta ou muito alta (84\%).

Em relação à percepção da SD como instrumento de sensibilização, aumento no interesse sobre o assunto, assim como estimulador do debater sobre o tema fora 
de sala de aula entre familiares e amigos, a maioria dos alunos consideram positiva a realização da SD (85\%, 92\% e 70\%, respectivamente).

Em relação ao diagnóstico da parte avaliativa do conteúdo trabalhado, foi possível observar que o HPV é a infecção com os sintomas mais conhecidos pelos alunos (85\%) e a gonorreia foi a que apresentou a menor taxa de acerto (46\%). Sobre os temas AIDS e sífilis, os percentuais de acerto foram 61 e $54 \%$, respectivamente.

Se considerarmos apenas as quatro questões sobre o conteúdo, a média da turma fica em torno de 61,5\%. Comparando os resultados dos questionários pré (63\%) e pós SD $(61,5)$, verificamos que a média pós SD foi menor, o que torna necessária uma reflexão sobre o resultado obtido. Um dos motivos que pode estar associado a esse resultado é o nível das questões apresentadas nos dois tipos de questionários. Enquanto o primeiro levou em consideração questões mais superficiais e gerais como situações cotidianas, o segundo possui questões mais técnicas sobre ISTs. Essa pôde ter sido a particularidade que mais influenciou o resultado negativo do segundo em relação do primeiro questionário. De qualquer forma, o questionário pós SD teve como maior finalidade o de examinar o efeito comportamental do estudante diante de todo trabalho realizado por meio de uma auto avaliação, pois segundo Lemos et al (2011) a auto avaliação possibilita o aluno a uma maior autonomia de aprendizagem tanto no período escolar quanto depois desse período. De toda forma obtivemos um resultado acima da média, o que foi um fato importante para tornar o uso da SD como um importante recurso de ensino e aprendizagem.

Avaliar não é simplesmente um ato de mensurar, comparar e quantificar, mas também o de apresentar importância política e social de determinado tema (KRAMER, 1991). Assim, os altos índices positivos obtidos quando se refere a auto avaliação são indicadores que mostram a relevância do uso dessa SD. 


\section{CONCLUSÕES}

Os anos de experiência em sala de aula permitem ao professor uma melhor percepção das particularidades presentes em seus alunos, particularidades essas expressas tanto na forma de agir, quanto na maneira de aprender, entre tantos outros aspectos sociais e pedagógicos. A partir da utilização de questionários pré e pós SD foi possível identificar, de forma geral, que os alunos já possuíam um conhecimento mediano sobre o tema, mas que, a partir da SD, sua compreensão tomou dimensões mais práticas e contextualizadas, sendo possível relacionar o assunto com situações do seu cotidiano, o que favorece para uma melhor sensibilização e conscientização visando uma melhor qualidade de vida. A professora que aplicou a SD percebeu um número superior de estudantes participando das diversas ações propostas ao longo do período e isso a fez envolver-se ainda mais em todo o processo pedagógico, o qual classificou como sendo bastante produtivo e exitoso.

A SD contemplou várias habilidades por meio de atividades de estímulo visual, oral, reflexivo, investigativo e criativo, muitas vezes de modo lúdico e com desempenho também associado a trabalhos em equipe. Toda essa gama de intervenções realizadas serviu para que, em pelo menos um momento, o aluno pudesse se identificar com a tarefa proposta e, desse modo, se motivar e executar de forma satisfatória. Desse modo constata-se que a carência de intervenções por meio de estratégias de ensino planejadas e executadas favorece a desmotivação e a baixa interação do aluno com o conteúdo, sendo fatores importantes no desempenho e favorecimento para a construção da aprendizagem.

A produção do livro paradidático foi um momento que se deve destacar por apresentar uma especificidade capaz de reunir em uma atividade o desenvolvimento de várias habilidades sendo que, a interação com a professora, a pesquisa e o trabalho em equipe, foram pontos de extrema importância para que os livros conseguissem ser elaborados e finalizados. A edição e impressão gráfica de um dos trabalhos indicam o meritório resultado dessa atividade. O momento de autógrafos 
culminou essa série de etapas de forma significativa e relevante, pois os alunos autores, através do desenvolvimento de sua autonomia em meio a todo esse processo, mostraram-se aptos a assumirem o protagonismo de seu ofício.

Mesmo ciente que é difícil identificar o momento da consolidação da aprendizagem, foi inegável não perceber a valiosa atuação participativa que os discentes demonstraram em várias etapas da intervenção, da aplicação dos questionários pré e pós SD, como no jogo de tabuleiro, nos debates propostos tanto nas rodas de conversa quanto na aula expositiva e dialogada, nas leituras em grupo e individual, no interesse por apresentar dúvidas e por tentar resolver problemas. Foram momentos importantes para a avaliação do conhecimento adquirido ao longo desse processo pedagógico e de significativa importância, visivelmente demonstrados pelos alunos. Portanto, espera-se que todo esse processo de aprendizagem desperte a criticidade e o compromisso na sensibilização da comunidade escolar e consequentemente na redução de casos de ISTs.

\section{Agradecimentos}

A Coordenação de Aperfeiçoamento de Pessoal de Nível Superior (CAPES) pela bolsa de mestrado concedida a Gemilton de Freitas Mesquita.

\section{REFERÊNCIAS}

ALTMANN H, MARTINS CJ. Educação sexual: ética, liberdade e autonomia. Educar em Revista. 2009;(35):63-80.

ALTMANN H. A sexualidade adolescente como foco de investimento político-social. Educação em Revista. 2007;(46):287-310.

ALVES WF. A formação de professores e as teorias do saber docente: contextos, dúvidas e desafios. Educação e Pesquisa. 2007;33(2):263-280.

AMORAS BC, CAMPOS AR, BESERRA EP. Reflexões sobre vulnerabilidade dos adolescentes a infecções sexualmente transmissíveis. PRACS: Revista Eletrônica de Humanidades do Curso de Ciências Sociais da UNIFAP. 2015;8,(1)163-171. 
ARAGÃO JS, FRANÇA ISX, COURA AS, MEDEIROS CCM, ENDERS BC. Vulnerabilidade associada às infecções sexualmente transmissíveis em pessoas com deficiência física. Ciência \& Saúde Coletiva. 2016;21(10):3143-3152.

AUSUBEL, DP, NOVAK JD, HANESIAN H. Psicología educativa: un punto de vista cognoscitivo. México: Trilhas; 1983.

EW RAS, CONZJ, FARIAS ADGDO, SOMBRIO PBM, ROCHA KB. Diálogos sobre sexualidade na escola: uma intervenção possível. Psicologia em Pesquisa. 2017;11(2):51-60.

FARID NDN, CHE'RUS S, DAHLUI M, AL-SADAT N, AZIZ NA. Predictors of sexual risk behaviour among adolescents from welfare institutions in Malaysia: a cross sectional study. BMC public health. BioMed Central. 2014;14(3):S9.

FERNANDES VR, FRISON LMB. Estratégias de aprendizagem autorregulatória no ensino superior: escrita de um artigo científico. Psicologia da Educação. Programa de Estudos Pós-Graduados em Educação: Psicologia da Educação. 2015;(41):37-49.

FERREIRA LNA, QUEIROZ SL. Textos de Divulgação Científica no Ensino de Ciências: uma revisão. Alexandria: Revista de Educação em Ciência e Tecnologia. 2012;5(1)3-31.

FREITAS DL. Pressupostos de uma Formadora em Educação Sexual: lições da prática. Revista Contexto \& Educação. 2012;27(88):35-61.

JOHAN CS, CARVALHO MS, ZANOVELLO R, OLIEIRA RPD, GARLET TMR, BARBOSA NBDV, MORESCO TR. Promovendo a aprendizagem sobre fungos por meio de atividades práticas. Ciência e Natura. 2014;36(II):799-805.

JÚNIOR APO, CIABOTTI V. Discussão sobre o processo de elaboração de um livro paradidático para o ensino de probabilidade à luz da teoria antropológica do didático. Revista de Ensino de Ciências e Matemática. 2018;9(2):52-71.

KRABBE EC, PADILHA AS, HENN A, MOLIN DBD, TEIXEIRA KJ, JÚNIOR PSA et al. Vacina contra o HPV e a prevenção do câncer do colo do útero: uma necessidade de avanço na prática cotidiana da ciência da saúde. Revista Interdisciplinar de Ensino, Pesquisa e Extensão. 2016;3(1):237-244.

KRAMER S. Com a pré-escola nas mãos: uma alternativa curricular para a educação infantil. São Paulo: Ática;1991.

LEMOS ES, MOREIRA MA. A avaliação da aprendizagem significativa em biologia: um exemplo com a disciplina embriologia. 2011. Meaningful Learning Review. 2011;1(2)15-26.

MACINTYRE AK, VEGA ARM, SAGBAKKEN M. From disease to desire, pleasure to the pill: A qualitative study of adolescent learning about sexual health and sexuality in Chile. BMC public health. 2015;15(1):945.

MATOS, LAD. Sumário de Didática Geral. Rio de Janeiro: Gráfica Editora Aurora;1971. 
MINISTÉRIO DA SAÚDE; Secretaria de Vigilância em Saúde. Departamento de DST, AIDS e hepatites virais. Boletim Epidemiológico AIDS e DST. Brasília (BRASIL): Ministério da Saúde; 2016.

Moura CB., Mantovani GD., Silva RMM, Tres B. Comparação de dúvidas sobre sexualidade entre crianças e adolescentes. Revista Contexto \& Educação. 2015;29(92):72-90.

OLIVEIRA PC, PIRES LM, JUNQUEIRA ALN, VIEIRA MAS, MATOS MA, CAETANO KAA, et al. Conhecimento em saúde sexual e reprodutiva: estudo transversal com adolescentes. Revista Eletrônica de Enfermagem. 2017;19:1-11.

OLIVEIRA, MM. Sequência didática interativa no processo de formação de professores. Petrópolis. Vozes; 2013.

PAIVA ALB, MARTINS CMC. Concepções prévias de alunos de terceiro ano do Ensino Médio a respeito de temas na área de Genética. Ensaio Pesquisa em Educação em Ciências. 2015;7(3):182-201.

SAVI R, ULBRICHT VR. Jogos digitais educacionais: benefícios e desafios. Renote. 2008;6(1):1-10.

SENNA SRCM, DESSEN MA. Reflexões sobre a saúde do adolescente brasileiro. Psicologia, Saúde \& Doenças. 2015;16(2): 217-229.

SILVA GB, FREITAS DS. Quando a genética vira notícia: o uso de textos de divulgação científica (TDC) em aulas de biologia. Revista Didática Sistêmica. 2006;3:41-56.

SILVA R. Quando a escola opera na conscientização dos jovens adolescentes no combate às DSTs. Educar em Revista. 2015;31(57):221-238.

SILVA SPC, BARBOSA APP, ARAÚJO CS, SILVA TIM, SANTANA RN. Discutindo sexualidade/IST no contexto escolar: práticas de professores de escolas públicas. Revista de Enfermagem UFPE online. 2016;10(5):4295-4303.

SOUZA, SC, DOURADO L. Aprendizagem baseada em problemas (ABP): um método de aprendizagem inovador para o ensino educativo. Holos. 2015;5:182-200.

TEIXEIRA QD, RIBEIRO AB, SANTOS MC, COSTA FJ. O lúdico no ambiente escolar: utilização de jogo para promoção e manutenção da alimentação saudável em uma escola particular da região metropolitana de Belo Horizonte. Revista Tecer 2016;9(16)44-56.

ZAGO LM, GOMES AC, FERREIRA HÁ, SOARES NS, GONÇALVES CA. Fotossíntese: uma proposta de aula investigativa. Revista Brasileira de Biociências. 2007;5(S1):759-761.

ZAPPE JA, SAUERWEIN IPS. Os pressupostos da educação pela pesquisa e o ensino de fungos: 0 relato de uma experiência didática. REEC: Revista Electrónica de Enseñanza de las Ciencias. 2018;17(2):476-490.

ZUANON ÁCA, DINIZ RHS, DO NASCIMENTO LH. Construção de jogos didáticos para o ensino de Biologia: um recurso para integração dos alunos à prática docente. Revista Brasileira de Ensino de Ciência e Tecnologia. 2011;3(3)49-59. 


\section{Contribuições de autoria}

\section{1 - Gemilton de Freitas Mesquita}

Mestre, professor da rede estadual de Pernambuco https://orcid.org/0000-0003-3278-7250 - gemiltonmesquita@gmail.com Contribuição: Conceituação, Metodologia, Análise Formal, Escrita - primeira redação, Escrita - revisão e edição

\section{2 - Aline Furtuozo de Souza}

Mestra, professora da rede estadual de Pernambuco https://orcid.org/0000-0002-6986-9981 - alinefurtuozo@yahoo.com.br Contribuição: Investigação

\section{3 - Thais Soares da Silva}

Mestra, doutoranda https://orcid.org/0000-0003-2305-4645 - thais.soares1994@gmail.com Contribuição: Investigação, Análise formal

\section{4 - Isabella Macário Ferro Cavalcanti}

Professora

https://orcid.org/0000000278893502 - isabella.cavalcanti@ufpe.br

Contribuição: Supervisão, Análise formal

\section{Como citar este artigo}

MESQUITA, G. F.; SOUZA, A. F; SILVA, T. S.; CAVALCANTI, I. M. F. Promovendo a aprendizagem sobre infecções sexualmente transmissíveis por meio de uma sequência didática. Ciência e Natura, Santa Maria, v. 43, e64, p. 1-27, 2021. Disponível em: https://doi.org/10.5902/2179460X39175. 